\title{
Self-reported health-related quality of life (HRQoL) and factors affecting HRQoL among individuals with health insurance in Iran
}

\author{
Ali Kazemi Karyani, Arash Rashidian, Sarar Emamgholipour Sefiddashti, Ali Akbari Sari \\ Department of Health Management and Economics, School of Public Health, Tehran University of Medical Sciences, Tehran, Iran
}

OBJECTIVES: The aim of this study was to measure the health-related quality of life (HRQoL) and to evaluate the factors affecting HRQoL in individuals with health insurance in Tehran, Iran.

METHODS: A cross-sectional analytical study was conducted using the 3-level EuroQol 5-dimensions (EQ5D) questionnaire. In order to estimate the determinants of HRQoL, information about participants' demographic, socioeconomic, and health status was gathered. The cluster sampling technique was used to collect data from May to June, 2016. The chi-square test and weighted least squares method were employed for data analysis. Data were analyzed using Stata version 11.0.

RESULTS: A total of 600 Iranians with insurance completed the study, of whom 327 (54.5\%) were male and $273(45.5 \%)$ were female. The mean age of the participants was 41.48 years (standard deviation [SD], 14.60 years). Meanwhile, the mean duration of education was 12.36 years (SD, 4.68 years). The mean EQ-5D score was 0.74 (SD, 0.16). The most common health problems in the participants were anxiety/depression (42.3\%), followed by pain/discomfort (39.2\%). Sex, age, years of schooling, income, chronic disease, and body mass index had a significant effect on HRQoL $(\mathrm{p}<0.05)$. Healthy insured individuals, on average, had a HRQoL score 0.119 higher than that of people with a chronic disease, all else being equal $(p<0.001)$.

CONCLUSIONS: Among all determinants of HRQoL, chronic disease was found to be the highest priority for interventions to improve the health status of Iranians with insurance. This finding can help policymakers and health insurance organizations improve their planning to promote the HRQoL of individuals with insurance and society as a whole in Iran.

KEY WORDS: Health related quality of life, Quality of life, Health, Insurance, Iran

\section{INTRODUCTION}

Health-related quality of life (HRQoL) is a measure that reflects individuals' subjective experiences of their health status.

\section{Correspondence: Arash Rashidian}

Department of Health Management and Economics, School of Public Health, Tehran University of Medical Sciences, Poursina Ave., Tehran 1417613151, Iran

Tel: +98-2188989129, Fax: +98-2166424538

E-mail: arashrashidian@gmail.com

Received: Aug 31, 2016, Accepted: Oct 26, 2016, Published: Oct 26, 2016 This article is available from: http://e-epih.org/ (C) 2016, Korean Society of Epidemiology

(C) This is an open-access article distributed under the terms of the Creative Commons Attribution License (http://creativecommons.org/licenses/by/4.0/), which permits unrestricted use, distribution, and reproduction in any medium, provided the original work is properly cited.
HRQoL systematically focuses on measuring the relationship between health and health status with quality of life (QoL) [1,2]. It is a dynamic multidimensional model and it consists of three main dimensions: the physical, social, and mental dimensions of health [3].

In order to improve the QoL in various populations and to reduce health inequalities, it is important to note that certain domains and the factors related to those domains might be especially influential for subjects' HRQoL [3,4]. Therefore, many researchers have examined HRQoL and the factors affecting population health and health-related conditions, based on the hypothesis that this is an optimal way to characterize the severity of these problems [5-7]. However, HRQoL has not been thoroughly characterized among those with health insurance. Health insurance coverage has a tremendous impact on access to healthcare services. Moreover, people with health insurance have bet- 
ter physical and mental health than those who are not insured [8-10].

In Iran, the health system is insurance-based, which has had an important effect on the healthcare system in the country [11]. The Social Security Organization, which was renamed the Social Security Insurance Organization (SSIO) in 1980, has provided health insurance coverage for almost all Iranian employees since 1975. Subsequently, the Medical Services Insurance Organization, which is currently known as the Iran Health Insurance Organization (IHIO), was established in 1994 in order to provide health insurance coverage for both governmental employees and those who had not yet been insured [11]. More than 1,670,000 people have IHIO insurance in Tehran city. Meanwhile, approximately six million people have SSIO insurance in Tehran city [12,13]. Evidence has been published regarding the HRQoL of patients with many diseases and chronic conditions in Iran $[14,15]$. Nonetheless, insufficient evidence-based information regarding HRQoL and its determinants within the essential health and health-related insurance system in Tehran and throughout Iran has been published. Given the lack of key evidence for policymakers in the country, we were selected all individuals with insurance as the study population. Most Iranians have health insurance, and we chose to focus on the insured people because they comprise a representative subset of the population in Tehran. Therefore, the aim of this study was to measure HRQoL and determine factors related to HRQoL in individuals with basic health insurance in Tehran, Iran. We additionally examined the dimensions of health according to age.

\section{MATERIALSAND METHODS}

This study was conducted in Tehran, the capital city of Iran. A cross-sectional analytical study was performed, in which the 3-level EuroQol 5-dimensions (EQ-5D) questionnaire was used to measure the participant's QoL and to estimate the quality of life determinants among insured individuals, including their socioeconomic factors and health status. The study was conducted among 600 people who had contacted a health insurance agency to buy new insurance or renew their previous insurance contract from May to June, 2016.

We sampled insured individuals in Tehran, Iran prior to the study. The study population consisted of all people who visited the two main insurance agencies, Social Health Insurance (SHI) and Iranian Health Insurance (IHI), who fulfilled the inclusion criteria of the study. All people who visited the SHI and IHI offices and who consented to participate in the study voluntarily were included. However, participants who were less than 18 years old or had cognitive problems were excluded from this study. A cluster sampling technique was used to collect data.
For this purpose, Tehran was divided into northern, southern, western, eastern and central areas. One branch of the SSIO and IHIO was selected from each area. Finally, the participants were selected by convenience sampling. The number of participants in each branch was determined proportionally according to the insured population covered by each branch. The sampling ended when the target number of participants in each branch was reached.

\section{Instrument and measurement}

An interviewer-administrated questionnaire was used to measure QoL and to identify the determinants of QoL among the insured. QoL was measured using the EQ-5D, which consists of items classified into five dimensions: mobility, self-care, usual activity, pain/discomfort, and anxiety/depression. Each item is answered using one of three responses: no problem, some problems, and extreme problems. The EQ-5D is a standard measurement scale for measuring QoL [2]. This study used the Iranian value set for EQ-5D health states in order to calculate participants' QoL. This value set was derived using the visual analog scale method [16]. Socioeconomic variables are basic predictors of health and QoL $[4,17]$. Consequently, these variables and demographic variables were also included in this study.

\section{Statistical analysis}

The analysis was performed using the descriptive characteristics of HRQoL status and insurance categories. Body mass index (BMI, $\mathrm{kg} / \mathrm{m}^{2}$ ) was calculated by dividing the weight (in kilograms) of an individual by her/his height (in meters) squared [18]. We also categorized BMI into three groups using the World Health Organization standard cut-off points: normal range, BMI $<25 \mathrm{~kg} / \mathrm{m}^{2}$; overweight, $25 \mathrm{~kg} / \mathrm{m}^{2} \leq \mathrm{BMI}<30 \mathrm{~kg} / \mathrm{m}^{2}$; and obese, $\mathrm{BMI} \geq 30 \mathrm{~kg} / \mathrm{m}^{2}$ [19]. We created a categorical variable including two types of health insurance combinations to evaluate whether insurance status modified the association between health insurance and HRQoL. The QoL scores were categorized into three groups: low $(\mathrm{QoL}<0.5)$, moderate $(0.5 \leq \mathrm{QoL}<0.8)$, and high (QoL $\geq 0.8)$. Furthermore, in order to test the hypothesis that QoL scores were independent of other variables (sex, age, etc.), the chi-square test was performed. Variables such as age and years of schooling were categorized. However, for variables such as marital status, employment status, and type of health insurance, some groups were merged to meet the assumptions of the chi-square test [20]. Consequently, regression analysis was performed to estimate the effects of the variables in a single model. Heteroscedasticity was found in the model. Therefore, weighted least squares regressions were constructed to model HRQoL measures in relation to HRQoL and insurance status. Therefore, variables that had a significant dependency with QoL using the chi-square test were included in the regres- 
sion model. The Ramsey Regression Equation Specification Error Test showed that there were no omitted variables. The final model was as follows:

$\mathrm{QoL}=\beta_{0}+\beta_{1}$ sex $+\beta_{2}$ age $+\beta_{3}$ mari $+\beta_{4} y$ sch $+\beta_{5}$ inc + $\beta_{6} e m p+\beta_{7}$ chd $+\beta_{8} B M I$ where sex refers to sex, age to age, mari to marital status, ysch to years of schooling, inc to income, emp to employment status, chd to chronic disease(s), and BMI to body mass index. We used Stata version 11.0 (StataCorp, College Station,TX, USA) for all statistical analyses in the study.

Table 1. Variations in quality of life (QoL) among individuals with health insurance in Tehran, Iran, 2016

\begin{tabular}{|c|c|c|c|c|c|}
\hline & \multicolumn{4}{|c|}{ QoL } & \multirow{2}{*}{ p-value } \\
\hline & Low & Moderate & High & Total & \\
\hline Overall & $51(8.5)$ & $316(52.7)$ & $233(38.8)$ & 600 & \\
\hline \multicolumn{6}{|l|}{ Sex } \\
\hline Male & $13(4.0)$ & $171(52.3)$ & $143(43.7)$ & 327 & $<0.001$ \\
\hline Female & $38(13.9)$ & $145(53.1)$ & $90(33.0)$ & 273 & \\
\hline \multicolumn{6}{|l|}{ Age (yr) } \\
\hline $18-29$ & $2(1.4)$ & $64(44.1)$ & $79(54.5)$ & 145 & $<0.001$ \\
\hline $30-39$ & $8(4.7)$ & $83(48.8)$ & $79(46.5)$ & 170 & \\
\hline $40-49$ & $14(14.0)$ & $60(60.0)$ & $26(26.0)$ & 100 & \\
\hline $50-59$ & $15(15.8)$ & $53(55.8)$ & $27(28.4)$ & 95 & \\
\hline$\geq 60$ & $12(13.3)$ & $56(62.2)$ & $22(24.4)$ & 90 & \\
\hline \multicolumn{6}{|l|}{ Marital status } \\
\hline Single & $5(3.0)$ & $80(48.8)$ & $79(48.2)$ & 164 & $<0.001$ \\
\hline Married & $32(8.4)$ & $199(52.5)$ & $148(39.0)$ & 379 & \\
\hline Other (divorced/bereaved) & $14(24.6)$ & $37(64.9)$ & $6(10.5)$ & 57 & \\
\hline \multicolumn{6}{|l|}{ Head of household } \\
\hline Yes & $22(7.3)$ & $163(54.3)$ & $115(38.3)$ & 300 & 0.52 \\
\hline No & $29(9.7)$ & $153(51.0)$ & $118(39.3)$ & 300 & \\
\hline \multicolumn{6}{|l|}{ Insurance type } \\
\hline SSI & $38(8.5)$ & $232(52.0)$ & $176(39.5)$ & 446 & 0.85 \\
\hline$\| \mathrm{HI} /$ other & $13(8.4)$ & $84(54.5)$ & $57(37.0)$ & 154 & \\
\hline \multicolumn{6}{|l|}{ Complementary insurance } \\
\hline Yes & $14(6.7)$ & $114(54.8)$ & $80(38.5)$ & 208 & 0.48 \\
\hline No & $37(9.4)$ & $202(51.5)$ & $153(39.0)$ & 392 & \\
\hline \multicolumn{6}{|l|}{ Chronic disease(s) } \\
\hline Yes & $46(13.6)$ & $237(70.1)$ & $55(16.3)$ & 338 & $<0.001$ \\
\hline No & $5(1.9)$ & $79(30.1)$ & $178(67.9)$ & 262 & \\
\hline \multicolumn{6}{|l|}{ Smoking } \\
\hline Yes & $5(5.7)$ & $53(55.8)$ & $37(38.9)$ & 95 & 0.45 \\
\hline No & $46(9.1)$ & $263(52.1)$ & $196(38.8)$ & 505 & \\
\hline \multicolumn{6}{|l|}{ Years of schooling } \\
\hline$<9$ & $22(19.0)$ & $65(56.0)$ & $29(25.0)$ & 116 & $<0.001$ \\
\hline $9-14$ & $23(10.3)$ & $115(51.6)$ & $85(38.1)$ & 223 & \\
\hline$\geq 14$ & $6(2.3)$ & $136(52.1)$ & $119(45.6)$ & 261 & \\
\hline \multicolumn{6}{|l|}{ Employment status } \\
\hline Employed & $12(3.8)$ & $161(50.9)$ & $143(45.2)$ & 316 & 0.001 \\
\hline Other (unemployed, housekeeper, retired, etc.) & $39(13.7)$ & $155(54.6)$ & $90(31.7)$ & 284 & \\
\hline \multicolumn{6}{|l|}{ Income (million IRR) } \\
\hline$<20$ & $42(13.7)$ & $154(50.3)$ & $110(35.9)$ & 306 & $<0.001$ \\
\hline $20-40$ & $9(2.9)$ & $104(34)$ & $76(24.8)$ & 189 & \\
\hline$\geq 40$ & $0(0)$ & $58(18.9)$ & $47(15.4)$ & 105 & \\
\hline \multicolumn{6}{|l|}{$\mathrm{BMI}\left(\mathrm{kg} / \mathrm{m}^{2}\right)$} \\
\hline$<25$ & $16(5.9)$ & $136(50.4)$ & $118(43.7)$ & 270 & $<0.001$ \\
\hline $25-30$ & $16(6.6)$ & $134(55.4)$ & $92(38.0)$ & 242 & \\
\hline$\geq 30$ & $19(21.6)$ & $46(52.3)$ & $23(26.1)$ & 88 & \\
\hline
\end{tabular}

Values are presented as number (\%).

SSI, Social Security Insurance; IHI, Iranian Health Insurance; IRR, Iranian rial; BMI, body mass index. 


\section{RESULTS}

A total of 600 people with insurance participated in the study. The response rate was $93.5 \%$. 327 participants (54.5\%) were male and $273(45.5 \%)$ were female. The mean age of participants was 41.48 years (standard deviation [SD], 14.60 years). The mean duration of education was 12.36 years (SD, 4.68 years). The mean BMI was $25.75 \mathrm{~kg} / \mathrm{m}^{2}$ (SD, $\left.4.20 \mathrm{~kg} / \mathrm{m}^{2}\right)$. The majority of participants $(n=379,63.2 \%)$ were married, while $164(27.3 \%)$ were single and the remaining 57 (9.5\%) were divorced or bereaved. Participants with moderate QoL were more likely to be married than single. However, single participants showed a similar QoL (both moderate and high). Of the participants, 300 (50.0\%) were heads of households.

A total of 446 participants $(74.3 \%)$ were insured through SSI, while 154 (25.7\%) were ensured through other health insurance agencies, of whom 119 (19.8\%) had insurance through IHI. Furthermore, we found that the majority of the insured $(n=392,65.3 \%)$ did not have complementary health insurance. Of the participants, $316(52.6 \%)$ were employed.

Most participants $(n=306,51.0 \%)$ earned $<20$ million Iranian rials (IRR) monthly, and 189 (31.5\%) earned between 20 and 40 million IRR. Only 105 (17.5\%) earned 40 million IRR or more monthly. Meanwhile, 95 participants $(15.8 \%)$ were current smokers and 338 (56.3\%) were affected by chronic diseases in the study period. The mean HRQoL score was 0.74 (SD, 0.16).

The overall QoL was most commonly moderate $(52.7 \%$ of participants). Statistically significant differences in QoL were found according to sex, age, marital status, years of schooling, employment status, monthly income, chronic disease(s), and
BMI $(\mathrm{p}<0.001)$. However, no significant differences in QoL were found according to head of household status $(\mathrm{p}=0.52)$, insurance type $(p=0.85)$, complementary insurance $(p=0.48)$, and smoking status $(\mathrm{p}=0.45)$. It was also found that among individuals with moderate QoL score (0.5 to 0.8), 171 (54.1\%) were male and $145(45.9 \%)$ were female. In addition, the majority $(n=232,73.4 \%)$ of participants with moderate QoL score were insured by SSI and the remaining 84 (26.6\%) were insured by other insurance agencies.

Almost all of the variables that were related to QoL were associated with moderate QoL scores. However, 47 (44.8\%) of the insured who earned at least IRR 40 million monthly salary had high QoL scores $(\geq 0.80)$, and $178(67.9 \%)$ of the insured who are not affected by chronic diseases had a high QoL score $(\geq 0.80)$ (Table 1).

The EQ-5D indicated that respondents 50 to 59 years of age reported poorer health status. Respondents in this age group reported the highest proportion of problems with anxiety/depression $(44.2 \%)$. The proportion of respondents self-reporting their EQ-5D profile to be level 3 (extreme problems) was $0.0 \%$ in all age groups for the mobility, self-care and, usual activity dimensions. Respondents 18 to 29 years of age had the lowest proportion of individuals reporting problems with self-care $(0.7 \%)$, and the age group of 30 to 39 years had the lowest percentage of problems in the mobility dimension $(18.8 \%)$. The age group of 40 to 49 years had the lowest percentage of usual activity problems $(9.0 \%)$ (Table 2$)$.

Compared with the other age groups, the age group of 50 to 59 years reported significantly greater problems in the mobility, self-care, usual activity, and pain/discomfort dimensions of the EQ-5D. No significant differences were found in the proportion

Table 2. Proportions of level 1, 2, and 3 responses by dimension of the EuroQol 5-dimensions (EQ-5D) and by age group among individuals with health insurance in Tehran, Iran, 2016

\begin{tabular}{|c|c|c|c|c|c|c|c|}
\hline \multirow{2}{*}{$E Q-5 D$} & \multirow{2}{*}{ Level } & \multicolumn{6}{|c|}{ Age (yr) } \\
\hline & & $18-29$ & $30-39$ & $40-49$ & $50-59$ & $\geq 60$ & Total \\
\hline \multirow[t]{3}{*}{ Mobility } & 1 & 80.7 & 81.1 & 78.0 & 74.7 & 78.9 & 79.2 \\
\hline & 2 & 19.3 & 18.8 & 22.0 & 25.3 & 21.1 & 20.8 \\
\hline & 3 & 0.0 & 0.0 & 0.0 & 0.0 & 0.0 & 0.0 \\
\hline \multirow[t]{3}{*}{ Self-care } & 1 & 99.3 & 98.2 & 97.0 & 92.6 & 96.7 & 97.2 \\
\hline & 2 & 0.7 & 1.8 & 3.0 & 7.4 & 3.3 & 2.8 \\
\hline & 3 & 0.0 & 0.0 & 0.0 & 0.0 & 0.0 & 0.0 \\
\hline \multirow[t]{3}{*}{ Usual activity } & 1 & 89.0 & 90.6 & 91.0 & 83.2 & 88.9 & 88.8 \\
\hline & 2 & 11.0 & 9.4 & 9.0 & 16.8 & 11.1 & 11.2 \\
\hline & 3 & 0.0 & 0.0 & 0.0 & 0.0 & 0.0 & 0.0 \\
\hline \multirow[t]{3}{*}{ Pain/discomfort } & 1 & 57.9 & 64.7 & 61.0 & 54.7 & 64.4 & 60.8 \\
\hline & 2 & 40.7 & 35.3 & 39.0 & 42.1 & 34.4 & 38.2 \\
\hline & 3 & 1.4 & 0.0 & 0.0 & 3.2 & 1.1 & 1.0 \\
\hline \multirow[t]{3}{*}{ Anxiety/depression } & 1 & 55.9 & 57.1 & 62.0 & 55.8 & 58.9 & 57.7 \\
\hline & 2 & 39.3 & 38.8 & 37.0 & 38.9 & 40.0 & 38.8 \\
\hline & 3 & 4.8 & 4.1 & 1.0 & 5.3 & 1.1 & 3.5 \\
\hline
\end{tabular}


of participants who reported problems in the usual activity and anxiety/depression dimensions between 18 and 49 years of age. Compared with the overall rate of problems reported in each age groups, a significantly higher proportion of participants re- ported problems in the anxiety/depression dimension. Therefore, the highest percentage of participants who reported problems in the pain/discomfort (45.2\%) and anxiety/depression $(44.2 \%)$ dimensions were in the 50 to 59 years-old age group.

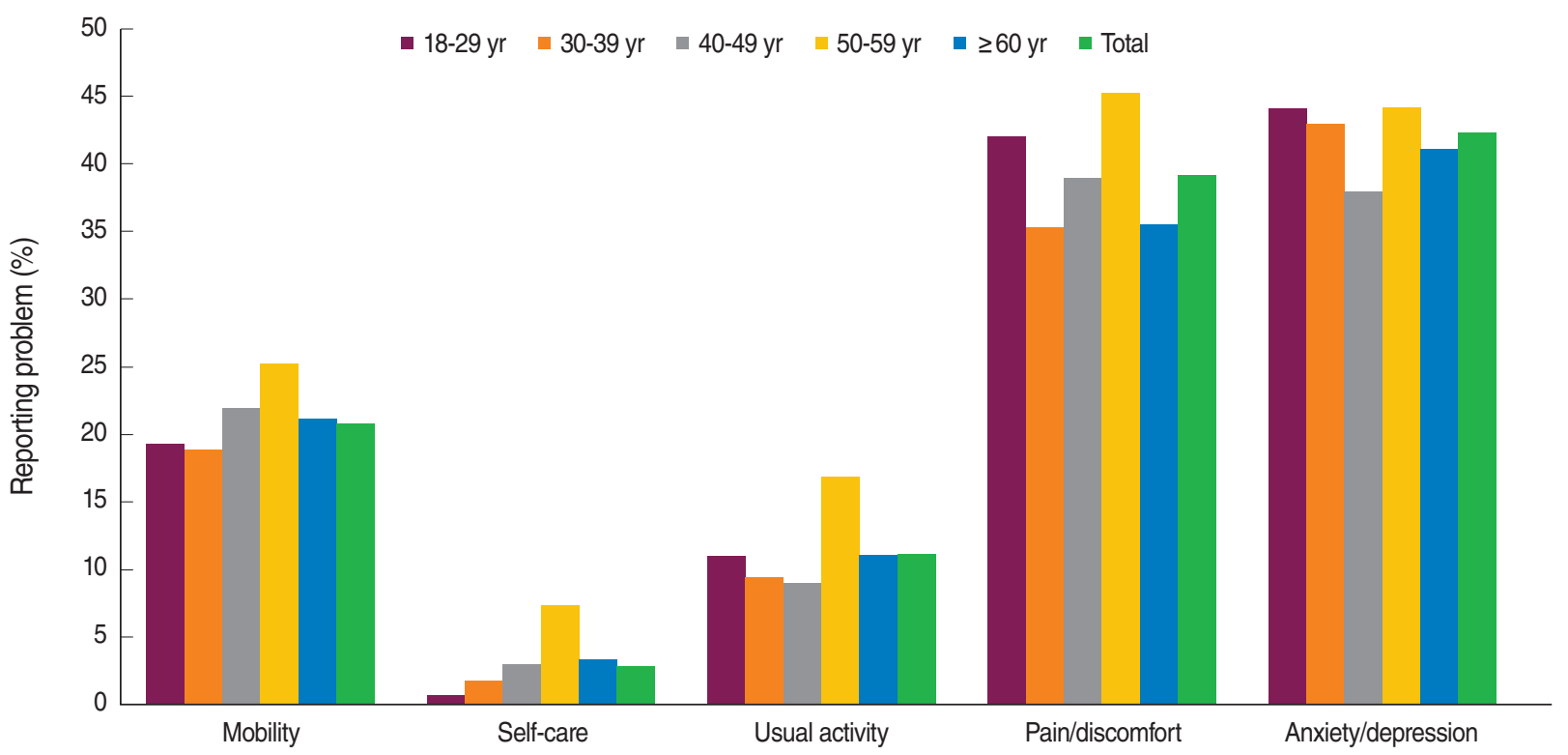

Figure 1. Percentage distribution of reporting problems among health Insured in Tehran city, Iran, 2016.

Table 3. Regression analysis results of quality of life among individuals with health insurance in Tehran, Iran, 2016

\begin{tabular}{|c|c|c|c|c|c|}
\hline & S Lfirion & R & 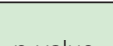 & & \\
\hline & p-coencient & RODUST SE & p-value & Upper limit & Low limit \\
\hline Sex (ref: male) & & & & & \\
\hline Female & -0.047 & 0.013 & $<0.001$ & -0.072 & -0.021 \\
\hline Age (ref: 18-29, yr) & & & & & \\
\hline $30-39$ & -0.013 & 0.013 & 0.33 & -0.039 & 0.013 \\
\hline $40-49$ & -0.050 & 0.019 & 0.01 & -0.089 & -0.012 \\
\hline $50-59$ & -0.042 & 0.021 & 0.05 & -0.084 & 0.000 \\
\hline$\geq 60$ & -0.046 & 0.023 & 0.04 & -0.091 & -0.001 \\
\hline Marital status (ref: single) & & & & & \\
\hline Married & 0.012 & 0.013 & 0.34 & -0.013 & 0.037 \\
\hline Divorced/ bereaved & -0.024 & 0.029 & 0.40 & -0.081 & 0.032 \\
\hline Years of schooling (ref: 0-8) & & & & & \\
\hline $9-13$ & 0.030 & 0.020 & 0.14 & -0.010 & 0.069 \\
\hline $14+$ & 0.050 & 0.018 & 0.007 & 0.014 & 0.086 \\
\hline Income (ref: <20 million IRR) & & & & & \\
\hline $20-40$ & 0.023 & 0.013 & 0.07 & -0.002 & 0.048 \\
\hline$\geq 40$ & 0.035 & 0.015 & 0.02 & 0.005 & 0.066 \\
\hline Employment status (ref: employed) & & & & & \\
\hline Other (unemployed, housekeeper, retired, etc.) & -0.010 & 0.013 & 0.44 & -0.035 & 0.015 \\
\hline Chronic disease(s) (ref: yes) & & & & & \\
\hline No & 0.119 & 0.011 & $<0.001$ & 0.097 & 0.141 \\
\hline BMI & -0.004 & 0.001 & 0.03 & -0.007 & -0.000 \\
\hline Constant & 0.792 & 0.047 & $<0.001$ & 0.699 & 0.884 \\
\hline$F(12,586)=19.17$ & & $>F=0.000$ & & & \\
\hline
\end{tabular}

$\mathrm{SE}$, standard error; $\mathrm{Cl}$, confidence interval; IRR, Iranian rial; BMI, body mass index. 
Overall, participants 50 to 59 years of age and $\geq 60$ years of age had more problems in all EQ-5D dimensions (Figure 1).

The results of regression analysis predicting the eight outcome variables after controlling for the characteristics of the insured found that the average QoL score in females was 0.047 lower than in males $(p<0.001)$. The variables showing the strongest associations were sex, years of schooling, and chronic diseases. Marital status, income (in the category of IRR 20 to 40 million monthly) and employment status were not significantly related to QoL. However, the variables showing slight associations with QoL were age, marital status, income, BMI, and employment status. The healthy insured had a QoL score 0.119 greater than people with a chronic disease $(\mathrm{p}<0.001)$. Moreover, each unit increase of BMI yielded a 0.004 unit decrease in QoL $(p<0.05)$. The $\mathrm{R}^{2}$ of the model was 0.32 and the model was statistically significant $(\mathrm{p}<0.001)$ (Table 3).

\section{DISCUSSION}

This study measured HRQoL and determined the effects of factors related to HRQoL, using the EQ-5D to measure outcomes among individuals with basic insurance and their QoL. We found that the greatest proportion of problems such as anxiety/depression was reported by individuals 50 years of age and older.

This study is supported by a previous study [16] showing that pain/discomfort was the most common health problem (34.4\%) and that $33.4 \%$ of the population suffered from anxiety/depression in Tehran. Similar studies have shown that most problems in the general population related to the pain/discomfort and anxiety/depression dimensions of HRQoL. This study revealed that individuals with insurance aged 18 to 44 years had the lowest proportion of problems with mobility, self-care, and usual activity. Similarly, self-care was the least prevalent health problem in these subjects $[4,21,22]$.

This study suggested that HRQoL significantly varied with sex. The mean EQ-5D values in Sweden (0.85) [4], in the US (0.87) [23] and in Italy (0.96) [22] were higher than our study (0.74). The SD of the scores in all these studies was lower than ours, as well. Other studies $[22,24]$ have shown that QoL for females is lower than for males. Moreover, with increasing age, QoL decreases. Another study [25] that investigated HRQoL in the elderly population in Tehran showed that elderly individuals suffered from poor QoL. Furthermore, females and lower education levels were associated with lower HRQoL. In many studies, people with higher income and education reported higher HRQoL scores $[4,24,26,27]$. Nonetheless, some studies did not report a significant difference in QoL based on sexes [21]. Our results also showed that no significant difference was found in
QoL according to insurance type, complementary insurance, or smoking status. Similar to our study, the causal relationship between income and health status was not clear, but this information may be very valuable for policymakers nonetheless [24].

Some evidence suggests that QoL is negatively affected by smoking [22]. Additionally, patients with chronic diseases who smoke have a lower health status than never smokers [28].

This study provides evidence that QoL was strongly associated with monthly income, chronic diseases, and BMI. High BMI had significant negative effects on HRQoL. However, a previous study [4] showed that QoL scores were not correlated with marital status or employment patterns. Therefore, it seems that more studies are needed to clarify the correlation between these variables and QoL. Similarly, many studies have shown the negative impact of excess body weight on QoL [29,30]. Additionally, some other studies have shown that obese people who do not have chronic diseases have a lower QoL than people with a normal weight [31]. It has previously been reported that adults with a higher than normal BMI have poorer physical and mental QoL than people with normal weight and that people with a higher class of obesity have poorer QoL [29,30]. A national survey in Iran [15] showed that people with type 2 diabetes, as a prevalent chronic disease, had poor HRQoL, especially in the pain/discomfort and anxiety/depression dimensions of HRQoL.

Our findings indicate that the overall QoL among the insured was moderate. In addition, this study revealed that sex, years of schooling, and chronic diseases were strongly associated with QoL. A similar study [24] showed that females, lower education, unemployment, and hospitalization due to diabetes and side effects of the disease were correlated with lower QoL and reporting some or extreme problems in various dimensions. Moreover, the difference in QoL scores between people with and without any disease was approximately 0.064 , which is less than what we found (0.119). Another study [32] also indicated that patients with coronary heart disease in both sexes had lower QoL scores than the general population and a higher percentage of reported problems in the anxiety/depression dimension of EQ-5D. In addition, some evidence shows that people with chronic conditions have poorer physical and mental QoL [33], and that those with more severe disease have poorer QoL [34]. However, therapeutic interventions may have a significant impact on improving QoL in these patients [33,34].

We used convenience sampling for data gathering and it was not possible to select participants randomly. Additionally, participants were asked to provide their weight and height to calculate their BMI. Therefore, it is possible that some errors occurred in this variable.

The findings of our study contribute to improved perceptions of individuals' own health status and QoL in Iran. The attention of policymakers, insured individuals, and communities in gen- 
eral should be focused on the effects of the factors affecting insurance status and HRQoL. Moreover, chronic diseases are the highest priority for interventions to improve the health status of individuals with insurance. This evidence can help policymakers and health insurance organizations to improve their planning to promote HRQoL among insured individuals and society as a whole.

\section{ACKNOWLEDGEMENTS}

This paper was part of the $\mathrm{PhD}$ thesis of Ali Kazemi Karyani. This research was funded by the Tehran University of Medical Sciences (no. 29725) and Social Security Research Institute (no. 395002684). Then, the authors would like to thank the Tehran University of Medical Sciences and Social Security Research Institute for their financial support. We also thank the Social Security Insurance Organization (SSIO) and Iran Health Insurance Organization (IHIO) for assistance with the data gathering process.

\section{CONFLICT OF INTEREST}

The authors have no conflicts of interest to declare for this study.

\section{ORCID}

Ali Kazemi Karyani http://orcid.org/0000-0002-4448-9317

Arash Rashidian http://orcid.org/0000-0002-4005-5183

Sarar Emamgholipour Sefiddashti http://orcid.org/0000-

0002-3653-3082

Ali Akbari Sari http://orcid.org/0000-0002-6933-4071

\section{REFERENCES}

1. Saarni SI, Härkänen T, Sintonen H, Suvisaari J, Koskinen S, Aromaa A, et al. The impact of 29 chronic conditions on health-related quality of life: a general population survey in Finland using 15D and EQ5D. Qual Life Res 2006; 15:1403-1414.

2. van Reenen M, Oppe M. EQ-5D-3L user guide: basic information on how to use the EQ-5D-3L instrument; 2015 [cited 2016 Nov 6]. Available from: http://www.euroqol.org/fileadmin/user_upload/Documenten/PDF/Folders_Flyers/EQ-5D-3L_UserGuide_2015.pdf.

3. Saharinen T, Koivumaa-Honkanen H, Hintikka J, Kylmä J, Lehto SM, Honkalampi K, et al. The effect of long-term life dissatisfaction on health-related quality of life among general population subjects. $\mathrm{J}$ Psychiatr Ment Health Nurs 2014;21:755-763.

4. Burström K, Johannesson M, Diderichsen F. Health-related quality of life by disease and socio-economic group in the general population in Sweden. Health Policy 2001;55:51-69.

5. Saffari M, Koenig HG, Pakpour AH, Sehlo MG. Health related quality of life among military personnel: what socio-demographic factors are important? Appl Res Qual Life 2015;10:63-76.

6. Soh SE, McGinley JL, Watts JJ, Iansek R, Murphy AT, Menz HB, et al. Determinants of health-related quality of life in people with Parkinson's disease: a path analysis. Qual Life Res 2013;22:1543-1553.

7. Vogl M, Wenig CM, Leidl R, Pokhrel S. Smoking and health-related quality of life in English general population: implications for economic evaluations. BMC Public Health 2012;12:203.

8. Ware JE, Davies AR, Donald CA. Conceptualization and measurement of health for adults in the health insurance study: vol. V, general health perceptions; 1978 [cited 2016 Nov 6]. Available from: https:// www.rand.org/content/dam/rand/pubs/reports/2006/R1987.5.pdf.

9. Lurie N, Ward NB, Shapiro MF, Brook RH. Termination from MediCal--does it affect health? N Engl J Med 1984;311:480-484.

10. Schaller J, Stevens AH. Short-run effects of job loss on health conditions, health insurance, and health care utilization. J Health Econ 2015; 43:190-203.

11. Davari M, Haycox A, Walley T. The Iranian health insurance system; past experiences, present challenges and future strategies. Iran J Public Health 2012;41:1-9.

12. Iranian Social Security Organization. Annual reports [cited 2016 Jul 2] Available from: http://www.tamin.ir/News/Item/3417/2/3417.html.

13. Salamat News. The statistical report of health insured in Iran [cited 2016 Oct 24]. Available from: http://www.salamatnews.com/news/ 178639/(Persian).

14. Rohani C, Abedi HA, Omranipour R, Langius-Eklöf A. Health-related quality of life and the predictive role of sense of coherence, spirituality and religious coping in a sample of Iranian women with breast cancer: a prospective study with comparative design. Health Qual Life Outcomes 2015;13:40.

15. Javanbakht M, Abolhasani F, Mashayekhi A, Baradaran HR, Jahangiri noudeh Y. Health related quality of life in patients with type 2 diabetes mellitus in Iran: a national survey. PLoS One 2012;7:e44526.

16. Goudarzi R, Zeraati H, Akbari Sari A, Rashidian A, Mohammad K. Population-based preference weights for the EQ-5D health states using the visual analogue scale (VAS) in Iran. Iran Red Crescent Med J 2016;18:e21584.

17. Kagamimori S, Gaina A, Nasermoaddeli A. Socioeconomic status and health in the Japanese population. Soc Sci Med 2009;68:21522160.

18. Sach TH, Barton GR, Doherty M, Muir KR, Jenkinson C, Avery AJ. The relationship between body mass index and health-related quality of life: comparing the EQ-5D, EuroQol VAS and SF-6D. Int J Obes (Lond) 2007;31:189-196.

19. World Health Organization. Global database on body mass index: BMI classification [cited 2016 Jun 18]. Available from: http://apps. who.int/bmi/index.jsp?introPage=intro_3.html.

20. McHugh ML. The chi-square test of independence. Biochem Med (Zagreb) 2013;23:143-149.

21. Clemens S, Begum N, Harper C, Whitty JA, Scuffham PA. A comparison of EQ-5D-3L population norms in Queensland, Australia, estimated using utility value sets from Australia, the UK and USA. Qual Life Res 2014;23:2375-2381.

22. Scalone L, Cortesi PA, Ciampichini R, Mantovani LG. Health related quality of life norm data of the general population in Italy: results using the EQ-5D-3L and EQ-5D-5L instruments. Epidemiol Biostat Public Health 2015;12:e11457.

23. Lu W, Cui Y, Chen X, Zheng Y, Gu K, Cai H, et al. Changes in qual- 
ity of life among breast cancer patients three years post-diagnosis. Breast Cancer Res Treat 2009;114:357-369.

24. Shiroiwa T, Fukuda T, Ikeda S, Igarashi A, Noto S, Saito S, et al. Japanese population norms for preference-based measures: EQ-5D-3L, EQ-5D-5L, and SF-6D. Qual Life Res 2016;25:707-719.

25. Tajvar M, Arab M, Montazeri A. Determinants of health-related quality of life in elderly in Tehran, Iran. BMC Public Health 2008;8:323.

26. Ferreira LN, Ferreira PL, Pereira LN, Oppe M. EQ-5D Portuguese population norms. Qual Life Res 2014;23:425-430.

27. Luo N, Johnson JA, Shaw JW, Feeny D, Coons SJ. Self-reported health status of the general adult U.S. population as assessed by the EQ-5D and Health Utilities Index. Med Care 2005;43:1078-1086.

28. Bremander A, Jacobsson LT, Bergman S, Haglund E, Löfvendahl S, Petersson IF. Smoking is associated with a worse self-reported health status in patients with psoriatic arthritis: data from a Swedish population-based cohort. Clin Rheumatol 2015;34:579-583.

29. Ul-Haq Z, Mackay DF, Fenwick E, Pell JP. Meta-analysis of the association between body mass index and health-related quality of life among adults, assessed by the SF-36. Obesity (Silver Spring) 2013; 21:E322-E327.
30. de Hollander EL, Picavet HS, Milder IE, Verschuren WM, Bemelmans WJ, de Groot LC. The impact of long-term body mass index patterns on health-related quality of life: the Doetinchem Cohort Study. Am J Epidemiol 2013;178:804-812.

31. Jia H, Lubetkin EI. The impact of obesity on health-related qualityof-life in the general adult US population. J Public Health (Oxf) 2005; 27:156-164.

32. Ghasemi E, Mohammad Aliha J, Bastani F, Haghani H, Samiei N. Quality of life in women with coronary artery disease. Iran Red Crescent Med J 2014;16:e10188.

33. Gerhold K, Richter A, Schneider M, Bergerhausen HJ, Demary W, Liebhaber A, et al. Health-related quality of life in patients with longstanding rheumatoid arthritis in the era of biologics: data from the German biologics register RABBIT. Rheumatology (Oxford) 2015; 54:1858-1866.

34. Younossi ZM, Stepanova M, Afdhal N, Kowdley KV, Zeuzem S, Henry L, et al. Improvement of health-related quality of life and work productivity in chronic hepatitis $\mathrm{C}$ patients with early and advanced fibrosis treated with ledipasvir and sofosbuvir. J Hepatol 2015;63:337345 . 